\title{
Annotations
}

\section{Diagnostic radiography in children}

The Japanese survivors of the atomic bombs are the largest group of people to be exposed to substantial doses of ionising radiation. They have been subjected to careful medical follow up that is continuing, and it is on the reports about these people that we chiefly depend in assessing the risk of cancer from ionising radiation. ${ }^{1}$ New estimates of the doses of radiation that they received, and the realisation that excess cancers are still appearing 40 years after the exposure, has led to substantial increases in our perception of the risks of ionising radiation. ${ }^{2}$ This increase in the perceived risks is most obvious with children, and this must lead to a reassessment of the hazards of paediatric diagnostic imaging by ionising radiation.

The units used to measure ionising radiation are the Gray (Gy), which is the dose absorbed by an organ, and the Sievert (Sv), the effective dose equivalent, which takes the dose absorbed by each organ and weights it according to the sensitivity of that organ to a lethal cancer or to the induction of serious genetic injury. The dose of radiation to a population is measured in man $\mathrm{Sv}$ and is the sum of the individual doses in Sv. The dose to the gonads is measured in Gy.

The harm that one man Sv causes used to be assessed at a $1 \%$ chance of developing a lethal cancer/man $\mathrm{Sv},{ }^{3}$ and there was an indication by an influential committee that the hazard was less than this in the young. ${ }^{4}$ New data are available concerning the risk of excess lethal cancer for children exposed to the atom bombs. ${ }^{2}$ Full interpretation of these data is awaited, but a possible risk of lethal cancer in children is $5 \% / \mathrm{Sv}$ in boys, and $9 \% / \mathrm{Sv}$ in girls. Table 1 is based on these risk factors. The considerably larger risk in girls is because the young girl's breast is extremely sensitive to radiogenic cancer. The new Japanese reports have not altered our perception of the magnitude of the genetic injury, which is based on animal and in vitro studies. Assuming an expectation of 1.6 offspring/child, the risk of serious genetic ill health within the first two generations is assessed at $1.6 \% / \mathrm{Gy}^{5}$

The dose of radiation received by a child during an $x$ ray examination varies depending particularly on the child's size and on the nature of the examination. Table 1 shows possible dosages for large and small children together with the number of examinations required to cause a lethal cancer. Note that the radiation dose from examination of a peripheral limb (for example, wrist or knee) is minute. Even an adult is likely to receive as high a dose from natural background radiation while the patient is in the department as from the examination. Table 2 gives possible doses to the gonads and the subsequent risks. These should be regarded as mean figures; variations in doses given to patients as large as tenfold have been reported between hospitals.

It will be noted that the doses for neonatal examinations are usually small. A neonate living in an area of low background radiation (such as

Table 1 Risk of lethal cancer after diagnostic radiography

\begin{tabular}{|c|c|c|c|}
\hline \multirow[t]{2}{*}{ Examination } & \multirow{2}{*}{$\begin{array}{l}\text { Approximate } \\
\text { dose of } \\
\text { radiation } \\
(\mathrm{mSv})\end{array}$} & \multicolumn{2}{|c|}{ Examinations/lethal cancer } \\
\hline & & $\begin{array}{l}\text { Male } \\
\text { patient }\end{array}$ & $\begin{array}{l}\text { Female } \\
\text { patient }\end{array}$ \\
\hline \multicolumn{4}{|l|}{ Small neonate: } \\
\hline Chest & $0 \cdot 01$ & $2 \times 10^{6}$ & $1 \cdot 1 \times 10^{6}$ \\
\hline Contrast meal & $0 \cdot 1$ & $2 \times 10^{5}$ & $1 \cdot 1 \times 10^{5}$ \\
\hline \multicolumn{4}{|l|}{ Large teenager:* } \\
\hline Chest & $0 \cdot 05$ & $4 \times 10^{5}$ & $2.2 \times 10^{5}$ \\
\hline Barium meal & $3 \cdot 83$ & 5000 & 3000 \\
\hline Lumbar spine & $2 \cdot 15$ & 9000 & 5000 \\
\hline Thoracic spine & 0.92 & 22000 & 12000 \\
\hline
\end{tabular}

${ }^{*}$ Adult doses of radiation. ${ }^{6}$

Table 2 Risk of genetic injury after diagnostic radiography

\begin{tabular}{|c|c|c|c|c|}
\hline \multirow[t]{2}{*}{ Examination } & \multicolumn{2}{|c|}{$\begin{array}{l}\text { Approximate dose } \\
\text { of radiation } \\
(m G y)\end{array}$} & \multicolumn{2}{|c|}{$\begin{array}{l}\text { Examinations/ } \\
\text { serious genetic } \\
\text { injury }\end{array}$} \\
\hline & $\begin{array}{l}\text { Male } \\
\text { patient }\end{array}$ & $\begin{array}{l}\text { Female } \\
\text { patient }\end{array}$ & $\begin{array}{l}\text { Male } \\
\text { patient }\end{array}$ & $\begin{array}{l}\text { Female } \\
\text { patient }\end{array}$ \\
\hline \multicolumn{5}{|l|}{ Neonatal: } \\
\hline Abdomen & 0.04 & 0.03 & $1.5 \times 10^{6}$ & $2 \times 10^{6}$ \\
\hline \multicolumn{5}{|l|}{ Large teenager:* } \\
\hline Chest & 0.0025 & 0.002 & $2.5 \times 10^{7}$ & $3 \times 10^{7}$ \\
\hline Abdomen & 1.6 & 0.8 & 40000 & 80000 \\
\hline Barium enema & $3 \cdot 4$ & 16 & 18000 & 4000 \\
\hline
\end{tabular}

${ }^{*}$ Adult doses of radiation. ${ }^{7}$ 
London or Manchester) would have to have 50 chest $x$ ray examinations before the ionising radiation he received before his first birthday exceeded the radiation received by a child who had had no chest $x$ ray examinations but lived in an area with high background radiation (such as Cornwall or Aberdeen). On the other hand the doses for the large teenagers are substantial, and the risks correspondingly high.

The doses of radiation from isotope examinations are also variable, depending especially on the type of examination. As the activity of the dose given in nuclear medical imaging is usually proportional to the patient's weight, the effective dose equivalent in children and adults is likely to be more similar than in $x$ ray diagnosis. Examples of possible doses are: ${ }^{99 \mathrm{~m}} \mathrm{Tc}$ brain scan $5.5 \mathrm{mSv}$, and renogram $0.2-$ $0.4 \mathrm{mSv}^{8}$

Radiation received by staff on a neonatal unit is generally negligible. If a newborn baby is held during a radiographic examination with the hand outside the primary beam, a million babies a year may be held by one person without the dose to the hand exceeding the dose limit allowed in industry. Even with the hand in the primary beam, 25000 exposures a year would be allowed. Somebody standing, with no lead protection, three metres from a neonate having a chest $x$ ray examination will receive about $0.00002 \mu \mathrm{Sv}$; this is about the same as the extra radiation received by spending one second in Cornwall rather than in Manchester. Exposure of staff to radiation during more complex procedures such as cardiac catheterisation is much greater, and there must be rigorous methods of protection.

The risk to a neonate from the radiation used in radiography is negligible. If there is a proper clinical indication for the examination there need be no hesitation in carrying it out. It is quite different in larger children, and the new perception of the risks in this group will lead to the avoidance of ionising radiation for other than the low dose examinations. Ultrasound and magnetic resonance imaging should be used where possible, and alternative techniques of diagnosis (such as endoscopy) must be encouraged.
The search for ways of lowering the doses of radiation is important. An antiscatter grid is unnecessary for fluoroscopy of neonates, and eschewing it will halve the radiation dose. ${ }^{9}$ Rare earth screens should always be used for children, and indeed adults, and at least halve the dose compared with simple tungstate screens. ${ }^{10}$ The use of carbon fibre material in certain components also causes a reduction in dose that can be as much as a further halving. ${ }^{11}$ Radiologists should ensure that these methods of reducing radiation are used in their departments.

\section{References}

1 Anonymous. Consequences of the new radiation dosimetry. Lancet 1987;i:1245-7.

2 Preston DL, Pierce ED. The effect of changes in dosimetry on cancer mortality risk estimates in the atomic bomb survivors. Hiroshima: Restriction Effects Research Foundation, 1987. (RERF Tech Rep No 9-87.)

3 International Commission on Radiological Protection. Recommendations of the ICRP. Oxford: Pergamon Press, 1977:26.

${ }^{4}$ Committee on the biological effects of ionizing radiations. The effects on populations of exposure to low levels of ionizing radiations. Washington: National Academy of Sciences, 1980.

5 United Nations Scientific Committee on the Effects of Atomic Radiation. Genetic and somatic effects of ionizing radiation. New York: United Nations, 1986.

6 Shrimpton PC, Wall BF, Jones DG, et al. A national survey of doses to patients undergoing a selection of routine X-ray examinations in English hospitals. Didcot: National Radiological Protection Board, 1986, R200.

7 Wall BF, Fisher ES, Shrimpton PC, Rae S. Current levels of gonadal irradiation from a selection of routine diagnostic X-ray examinations in Great Britain. Didcot: National Radiological Protection Board, 1980, R105.

${ }^{8}$ Shields RA, Lawson RS. Effective dose equivalent. Nucl Med Commun 1987;8:851-5.

" Gray JE, Swee RG. The elimination of grids during intensified fluoroscopy and photofluorospot imaging. Radiology 1982;144: 426-9.

11 International Commission in Radiological Protection. Protection of the patient in X-ray diagnosis. Oxford: Pergamon Press, 1970.

"Hufton AP, Russell JGB. The use of carbon fibre material in table tops, cassette fronts and grid covers: magnitude of possible dose reduction. Br J Radiol 1986;59:157-63.

J G B Russell St Mary's Hospital, Manchester M13 OJH 